\title{
A contrarreforma da educação superior brasileira no contexto da crise do capital
}

Agercicleiton Coelho Guerra ${ }^{1}$, Antonia Rozimar Machado e Rocha ${ }^{2}$, Marcela Figueira Ferreira ${ }^{3}$

\begin{abstract}
Resumo
O presente artigo discute as mudanças no ensino superior brasileiro a partir do contexto da crise estrutural do capital. Assim, buscamos relacionar como o desenvolvimento do sistema capitalista e as mudanças socioprodutivas atingem a educação brasileira e o ensino superior. A metodologia da pesquisa é de cunho bibliográficodocumental. Concluímos que o crescimento do setor privado no ensino superior possui uma estreita relação com as políticas econômicas adotadas nos países periféricos. Serviços essenciais como de saúde e educação passam pela privatização, atingindo a população não somente por essa via, mas também pela negação do acesso às instituições públicas de ensino superior e às áreas de conhecimento da universidade baseadas no tripé ensino, pesquisa e extensão.
\end{abstract}

\section{Palavras-chave}

Ensino superior. Neoliberalismo. Privatização.

\footnotetext{
${ }^{1}$ Doutorando em Educação na Universidade Estadual do Ceará, Brasil. E-mail: ageguerra@gmail.com.

2 Doutora em Educação pela Universidade Federal do Ceará, Brasil; professora adjunta e coordenadora pedagógica das licenciaturas nessa instituição. E-mail: profa.rosemachado@gmail.com.

${ }^{3}$ Mestranda em Educação Brasileira na Universidade Federal do Ceará, Brasil; professora da rede municipal de ensino de Fortaleza, Ceará, Brasil. E-mail: marcelaferreira8@gmail.com.
} 


\title{
The counter-reform of Brazilian higher education in the context of the capital crisis
}

\author{
Agercicleiton Coelho Guerra $^{4}$, Antonia Rozimar Machado e Rocha ${ }^{5}$, Marcela Figueira Ferreira ${ }^{6}$
}

\begin{abstract}
This article discusses the changes in Brazilian higher education from the context of the structural crisis of capital. Thus, we seek to relate how the development of the capitalist system and socio-productive changes affect Brazilian education and higher education. We will use as methodology the bibliographical research. We conclude that the growth of the private sector in higher education has a close relation with the economic policies adopted in peripheral countries. Essential services such as health and education go through privatization reaching the population not only through the privatization process, but also in the denial of access to public higher education institutions and knowledge areas of the university based on the tripod of teaching, research and extension.
\end{abstract}

\section{Keywords}

Higher education. Neoliberalism. Privatization.

\footnotetext{
${ }^{4} \mathrm{PhD}$ student in Education, State University of Ceará, State of Ceará, Brazil. E-mail: ageguerra@ gmail.com.

${ }^{5} \mathrm{PhD}$ in Education, Federal University of Ceará, State of Ceará, Brazil; associate professor and pedagogical coordinator of undergraduate courses at this institution. E-mail: profa.rosemachado@ gmail.com.

${ }^{6}$ Master student in Brazilian Education at the Federal University of Ceará, Brazil; teacher at the municipal education network in Fortaleza, Ceará, Brazil. E-mail: marcelaferreira8@gmail.com.
} 


\section{Introdução}

A partir das diversas mudanças internacionais causadas pela crise do capitalismo, pela reestruturação produtiva e pela mundialização do capital, o Brasil também passou por ajustes em sua política econômica e social. Assim, a educação superior e suas pesquisas foram alçadas como serviços não exclusivos do Estado que podem ser ofertados por Instituições de Ensino Superior (IES) da rede privada ou por organizações sociais no formato denominado público não estatal. A materialização de medidas de caráter reformista se expressou com mais intensidade a partir do governo de Fernando Henrique Cardoso (FHC) com a expansão do ensino superior privado, em decorrência de um conjunto de medidas expressas tanto no campo legal como operacional, por meio de Leis e Programas que, entre outras coisas, deslocaram recursos públicos para a inciativa privada no ensino superior brasileiro.

O artigo analisa o capitalismo contemporâneo no que se refere às suas transformações socioprodutivas e como elas têm influenciado o atual modelo de ensino superior. Examina, ainda, a "reforma" do Estado brasileiro e suas consequências na forma como o governo passou a gerenciar o ensino superior e situar a universidade pública no contexto da contrarreforma.

Para compreendermos os processos de ajuste que o ensino superior vem sofrendo nos últimos anos, é relevante entender como o capitalismo vem se reorganizando a partir de suas sucessivas crises e como se apropria da educação não só para reproduzir seus ideais de dominação, como afirma Mészáros (2002), mas utilizando a própria educação como mercadoria, dispondo-a no mercado geral como qualquer outro bem comercializável.

A metodologia escolhida para o trabalho foi a pesquisa bibliográfico-documental, que nos permitiu ter uma visão mais ampla de todo o processo educacional e político que envolve o tema escolhido. Partimos de estudos que abordam a estrutura da universidade brasileira e seu histórico, como, também, o modelo capitalista neoliberal da década de 1990 até sua fase atual, situando o papel que a universidade vem desempenhando e seu processo de massificação e produtivismo. Assim, para uma análise mais abrangente, será necessário realizamos um estudo sobre as implicações do capitalismo contemporâneo nas mudanças das relações socioprodutivas. Para isso, utilizamos as análises de Ricardo Antunes (1998) e David Harvey (1989), entre outros. Após as análises das mudanças apresentadas no contexto global, recorremos aos estudos de Carcanholo (2011), Bianchetti (2001), Boito Jr. (1999), Carinhato (2008) entre outros, para uma análise do modelo neoliberal como forma de sair das sucessivas crises iniciadas na década de 1970. 


\section{Crise do capital, transformações produtivas e Neoliberalismo}

Os desdobramentos da política educacional no Brasil se dão a partir de um contexto conjuntural específico, devido às crises econômicas de âmbito mundial, atingindo de forma aguda os países periféricos. Abordaremos como essas crises modificaram o modo de produção e a forma de gerir o Estado para que o sistema não entrasse em colapso.

As crises que abrangeram nos últimos cinquenta anos todo o sistema capitalista, mostram sua verdadeira forma e se colocam de modo latente em escala mundial. Como aponta Mészáros (2002), nos anos de 1970, o sistema capitalista entra em uma crise profunda inerente à sua própria existência ${ }^{7}$. Com efeito, o alicerce que sustenta o capitalismo está entrando em conflito e as possibilidades de reformá-lo estão se esgotando. Carcanholo (1996) ressalta que a causa do aparecimento da crise se expressa no fato de que o sistema de produção se desenvolve em larga escala, enquanto as condições de apropriação por parte da classe trabalhadora não acompanham esse desenvolvimento, ocorrendo a queda da taxa de lucro.

Os países periféricos, em relação àqueles países de capitalismo avançado, sofrem mais diretamente com os efeitos do sistema por viverem sob intensa exploração de mão-de-obra excedente, com o apoio de um Estado forte para manter sua influência política e deixar a mãode-obra barata atendendo aos interesses do capital, sem uma maior intervenção do Estado.

Antunes (2009) aponta alguns elementos que comprometeram a estabilidade do capitalismo, dentre os quais destacamos a queda da taxa de lucro, dada à grande concentração de capitais; a crise do Estado do Bem Estar Social; o esgotamento do modelo de produção taylorista fordista e; a crise da superprodução de mercadorias.

Para Antunes (1998), os anos a partir de 1970 foram marcados por uma grande inovação tecnológica que penetrou nas fábricas, influenciando as relações de trabalho. A partir desse contexto, diversos experimentos foram realizados, mesmo que de maneira inicial. O Toyotismo, como um desses processos, trouxe novos formatos de administração do trabalho, intensificando a exploração do operário, sem que tenha se dado conta dessa nova forma de manipulação. O just-in-time ou trabalho no tempo certo, originalmente elaborado por Henry Ford e aplicado por Taiichi Ohno no Japão, é um dos programas utilizados pelo

\footnotetext{
${ }^{7}$ Durante o apogeu da fase keynesiana e fordista, na qual ocorreu uma grande acumulação de capital, esse modelo começou a dar sinais de esgotamentos, como a queda da taxa de lucro e retração do consumo, resultando no avanço do desemprego estrutural e na crise do Estado, que não atendia mais às demandas sociais. Esses são só alguns pontos da crise de 1970, pois os elementos constitutivos são de grande complexidade (ANTUNES, 2009).
} 
toyotismo e tem como objetivo diminuir o desperdício do tempo na produção exigindo dos trabalhadores um movimento constante, nos prazos estabelecidos, além da extinção da linha de montagem, sendo substituída pelas ilhas de produção, com o objetivo de reduzir o tempo de espera na fabricação do produto (BORGES, 2005).

Como Harvey (1989) observa, os novos processos produtivos, apesar de todo o avanço tecnológico, retornam aos sistemas de trabalho doméstico, familiar e paternalista.

O retorno da superexploração em Nova Iorque e Los Angeles, do trabalho em casa e do "teletransporte", bem como o enorme crescimento das práticas de trabalho do setor informal por todo o mundo capitalista avançado, representa de fato uma visão bem sombria da história supostamente progressista do capitalismo. Em condições de acumulação flexível, parece que sistemas de trabalho alternativos podem existir lado a lado, no mesmo espaço, de uma maneira que permita que os empreendedores capitalistas escolham à vontade entre eles [...]. O mesmo molde de camisa pode ser produzido por fábricas de larga escala na Índia, pelo sistema cooperativo da "Terceira Itália", por exploradores em Nova Iorque e Londres ou por sistemas de trabalho familiar em Hong Kong. (HARVEY, 1989, p.175).

Como o autor demonstra, o avanço tecnológico trouxe mais exploração para a classe trabalhadora, retomando formas de trabalho mais precárias. Assim, paralelamente, crescem formas de subproletarização por meio de empregos temporários e um crescente avanço do trabalho informal (ANTUNES, 1998) e a acumulação flexível surge como uma forma de confrontar diretamente a rigidez que caracteriza o sistema fordista.

A acumulação flexível envolve rápidas mudanças dos padrões do desenvolvimento desigual, tanto entre setores como entre regiões geográficas, criando, por exemplo, um vasto "setor de serviços", bem como conjuntos industriais completamente novos em regiões até então subdesenvolvidas. (HARVEY, 1989, p. 140).

Conforme destaca Harvey (1989), para além das consequências no mundo do trabalho, o processo de acumulação flexível também atinge a cultura nos países de capitalismo avançado:

Para começar, o movimento mais flexível do capital acentua o novo, o fugido, o efêmero, o fugaz e o contingente da vida moderna, em vez dos valores mais sólidos implantados na vigência do fordismo. Na medida em que a ação coletiva se tornou, em consequência disso, mais difícil - tendo essa dificuldade constituído, com efeito, a meta central do impulso de incremento do controle do trabalho - o individualismo exacerbado se encaixa no quadro geral como condição necessária, embora não suficiente, da transição do fordismo para a acumulação flexível. Afinal de contas, foi principalmente por intermédio da irrupção da formação de novos negócios, da inovação e do empreendimento que muitos dos novos sistemas de produção vieram a ser implementados. (HARVEY, 1989, p.161). 
Dessa forma, o processo de acumulação flexível mudou o modo e os valores de vida da sociedade. $\mathrm{O}$ individualismo mais competitivo passou a ser um valor central na cultura da sociedade e áreas antes menos exploradas pelo capitalismo, como educação e a saúde, passaram a ocupar papel importante nas economias, como negócios lucrativos. O ensino superior também se ajustou à nova feição capitalista, que requer modelos mais pragmáticos e com geração imediata de resultados às questões demandadas pelo mercado.

$\mathrm{O}$ avanço tecnológico nos processos de trabalho exigiu um novo perfil de trabalhador para que o sistema pudesse ser efetivado com sucesso. Para atender à demanda mais individualizada de mercado e manter uma boa qualidade, a produção buscou um perfil de trabalhador que operasse com várias máquinas, quebrando a relação de um homem por máquina, como ocorria antes no sistema fordista (ANTUNES, 1998).

Entretanto, o sistema de acumulação flexível de modo algum diminui a exploração do trabalhador e, em alguns casos, até aprofunda, como nas fábricas em que se estabelece metas para o trabalho em equipe e grupos inteiros de trabalhadores ultrapassam seus horários, perfazendo amplas jornadas com o intuito de atingir as metas. $\mathrm{O}$ trabalhador, dentro desse sistema, passa a desempenhar múltiplas funções, além do aumento de horas extras exercidas por esses operários, na busca da indústria manter a produção. A consequência disso está no desemprego estrutural, jogando uma massa de operários para o setor de serviços, que cresceu bastante durante as décadas de 1980 e 1990.

Como consequência do processo de desproletarização fabril, aumentam o subproletariado, o trabalho precário e o assalariamento no setor de serviços. Há a inclusão do trabalho feminino, excluindo uma parcela dos mais jovens e dos mais velhos (ANTUNES, 1998).

Tumolo (2001) aponta que o processo de reestruturação produtiva no Brasil trata-se, na verdade, de uma desestruturação produtiva, pois intensificou o ritmo de trabalho, neutralizou a ação sindical e incorporou novas tecnologias na organização e gestão do trabalho. Dessa forma, temos empresas que misturam diversas formas de produção com o objetivo de intensificar a exploração do trabalho e evitar qualquer tipo de organização por parte da classe trabalhadora.

Isso explica porque não tem sido possível encontrar um "padrão produtivo" único ou mesmo uniforme nos vários países capitalistas, nem entre as próprias empresas e nem mesmo no interior delas. Na verdade, as empresas capitalistas vêm buscando a combinação mais adequada de "modelos produtivos", de acordo com as características de conjuntura - situação do país ou região onde estão instaladas, perfil da força de trabalho, histórico das 
lutas e formas de organização dos trabalhadores etc. - com o propósito de atingir os objetivos supra expostos. (TUMOLO, 2001, p.11).

Com a grande crise de 1970, o sistema capitalista buscou novas formas de superá-la retomando com mais vigor as concepções liberais e, assim, o neoliberalismo começou a ser aplicado como uma medida de enfrentamento da crise (CARCANHOLO; BARUCO, 2011).

Paniago (2008) define o Neoliberalismo como:

[...] um conjunto de medidas políticas, econômicas e sociais que visam tirar o capitalismo da crise e criar as condições necessárias para a recuperação da lucratividade da ordem global do capital em queda. Essas mesmas medidas intentam realizar objetivos diversos, a depender de quais interesses de classe procuram proteger. De um lado, observa-se uma série de medidas voltadas para a recuperação do lucro dos capitalistas, e de outro, imposições restritivas e autoritárias sobre a classe trabalhadora, cujo resultado é a degradação da sua qualidade de vida e trabalho. (PANIAGO, 2008, p. 2).

O Estado, dentro da teoria neoliberal, aparece como um mediador nas relações sociais, preservando um papel não regulamentador na relação com o mercado. Conforme Adam Smith, o Estado passa a operar a "mão invisível", assumindo uma função articuladora (BIANCHETTI, 2001).

A única intervenção estatal que os neoliberais apoiam, consiste na ação coercitiva, sob a justificativa de manter os interesses maiores da sociedade contra o avanço de poderes cerceadores da liberdade, que seriam as próprias forças democráticas (BIANCHETTI, 2001). Nesse sentido, o pensamento neoliberal tenta ao máximo desgastar a ideia de democracia. $\mathrm{O}$ modelo neoliberal não propõe a ampliação da participação, pois objetiva a manutenção dos grupos dominantes na sua condição hegemônica. Assim, os erros da democracia são combatidos com menos democracia e não com uma maior participação dos excluídos.

A concepção neoliberal defende a plena liberdade de organização e expansão da iniciativa privada, uma vez que o mercado, tendendo ao equilíbrio natural e guiado pela "mão invisível" e pelo individualismo utilitarista e egoísta, tem a capacidade de se autorregular, corrigindo eventuais desequilíbrios do capitalismo.

O que caracteriza o Neoliberalismo em relação a outras concepções liberais, está na ampliação da lógica do mercado, perpassando todas as esferas sociais. Assim, como afirma Marx (2002), no capitalismo nada escapa ao mercado, todas as relações sociais mais caras à humanidade curvam-se aos ditames do comércio, transformam-se em mercadorias. Sob o manto neoliberal, essas relações se agudizam ainda mais. De acordo com Bianchetti (2001, p. 88), “O Estado Mínimo aparece como uma consequência da lógica do mercado em todas as relações sociais, não reduzidas somente ao aspecto econômico". 
Apesar da mudança de ordem econômica e política, o Neoliberalismo não foi capaz de frear a alta taxa de desemprego. A ideia de Estado Mínimo (mínimo somente para a classe trabalhadora), por meio da redução da esfera de atuação estatal, também não reduziu os gastos do Estado, os quais são direcionados para outros setores.

Conforme Carcanholo e Baruco (2011, p. 12),

Diferentemente do que se possa pensar, o neoliberalismo não se define no nível de abstração da política econômica, isto é, não é porque as políticas monetária, fiscal e/ou cambial apresentam uma determinada característica (mais ortodoxa ou heterodoxa) que se define uma ideologia neoliberal ou antineoliberal. $\mathrm{O}$ neoliberalismo constitui uma estratégia de desenvolvimento capitalista, uma proposta de retomada estrutural do processo de acumulação de capital. Ainda que essa ideologia tenha se constituído antes, na prática, sua afirmação hegemônica e sua implementação são justamente a coloração ideológica do pós-crise dos anos 1960/70.

Com efeito, na medida em que o Estado se volta para a obtenção de mais capital a partir de uma menor intervenção em políticas sociais, mas, ao mesmo tempo, comprometido com o pagamento da dívida pública aos organismos multilaterais, não são observadas mudanças significativas no desemprego (CARCANHOLO; BARUCO, 2011).

No Brasil, as medidas econômicas e políticas inspiradas no modelo neoliberal de Estado começam a aparecer no governo Collor (1990-1992), mas somente no governo FHC (1995-2003) começam a ser aplicadas com mais vigor. Segundo Boito Jr. (1999), o Neoliberalismo brasileiro é tardio, comparado a outros países latino-americanos, além disso, tem encontrado mais dificuldades para avançar devido ao contexto de redemocratização e uma forte correlação de forças expressas por entidades sindicais e pelo Movimento dos Semterra. Antunes (2009) ressalta que, tanto nos países avançados como na periferia do capitalismo, o processo neoliberal retirou direitos dos trabalhadores e aumentou as condições precárias de emprego e ainda desacelerou o crescimento industrial do Brasil.

$\mathrm{Na}$ atual conjuntura nacional, o neoliberalismo avança em passos céleres sob o governo de extrema direita de Bolsonaro, retomando a contrarreforma do Estado da era FHC, implementando o tripé privatização, terceirização e público-não estatal. Está em curso, portanto, uma nova e mais agressiva onda contrarreformista que diminui ainda mais o raio de atuação do Estado, reduzindo seu papel social e ajustando-o às necessidades expansionistas do capital. 


\section{Elementos constitutivos da contrarreforma do ensino superior no contexto dos ajustes neoliberais do Estado: a privatização em marcha}

Com o fito de colaborar para a retomada da taxa de acumulação capitalista, estimulados pelos organismos multilaterais como o Banco Mundial e o Fundo Monetário Internacional (FMI), os Estados Nacionais precisam estar com orçamentos equilibrados e com estabilidade interna da moeda (COSTA, 2000). Assim, a tarefa de reformar os Estados é repassada aos países periféricos para que possam se ajustar ao "novo" cenário de liberalização de mercados.

Como destaca Costa (2000), o processo de liberalização do mercado é uma estratégia do grande capital, para que as regras de regulamentação em âmbito mundial sejam modificadas, favorecendo as grandes empresas multinacionais. A reforma dos Estados seria uma medida necessária para ajustá-los às necessidades prementes do capital de sair de sua crise estrutural.

O tema da Reforma do Estado ganhou espaço nos debates políticos e intelectuais durante a década de 1980. Os países que iniciaram as reformas liberais foram: Inglaterra, Estados Unidos, Nova Zelândia, Austrália e, ainda, vários outros países europeus como Alemanha e Itália. Na América Latina, Chile, México e Argentina foram os países que iniciaram as experiências de Reforma do Estado, ainda na década de 1980. Longe de ser um processo isento de contradições e de interesses, a Reforma do Estado foi identificada por vários intelectuais, como uma luta deflagrada pela elite econômica dos países centrais, na busca de ampliar suas ações no mercado mundial, desregulamentando a legislação trabalhista, destruindo a estrutura sindical e pressionando os países periféricos a abrirem seus mercados. (COSTA, 2000, p. 52-53).

A "reforma" veio se contrapor ao Estado de Bem-Estar-Social, colocando a máquina pública sob o crivo do modelo gerencial. Os movimentos reformistas no Brasil foram iniciados pelo ex-presidente Collor de Melo com algumas privatizações como da Usiminas, Petroflex, Alcanorte, Fosfértil, entre outras pequenas indústrias (CARINHATO, 2008).

FHC deu continuidade ao modelo de "reforma" estatal com o discurso de reestabelecer o crescimento e continuar a estabilização econômica. Criou o Ministério da Administração e Reforma do Estado (MARE), em 1995, cujo ministro, Bresser Pereira, tinha como principal função desenvolver o processo de reformulação do Estado (CARINHATO, 2008).

Aquele governo avaliou que o modelo de Estado desenvolvimentista tinha encontrado sua exaustão. Segundo FHC, para retomar o crescimento, era preciso que os excessos do Estado, que estavam localizados principalmente na área social, como saúde, educação, cultura 
e pesquisa científica, fossem retirados. Apesar das forças sociais realizarem um importante papel no recuo das propostas neoliberais, logo no seu primeiro mandato, não foi possível realizar uma forte contestação ao modelo que estava sendo aplicado, devido ao fato de FHC ter governado através de medidas provisórias, que contou com o consenso do Congresso Nacional, além do forte apoio da grande mídia, que discursava a favor das reformas constitucionais para garantir a estabilidade monetária e o controle do processo inflacionário (COSTA, 2000).

A descentralização do Estado foi implementada pela criação de agências autônomas e de organizações sociais. O governo passou a distribuir sua atuação em três setores, são eles: atividades exclusivas do Estado, atividades não exclusivas e o setor de produção de bens e serviços (ZANARDINI, 2007). Assim explica Pereira (2001, p. 38, grifos nossos),

\begin{abstract}
No domínio dos serviços não exclusivos, a definição do regime de propriedade é mais complexa. Se assumirmos que devem ser financiados ou fomentados pelo Estado, seja porque envolvem direitos humanos básicos (como educação e saúde), seja porque implicam externalidades envolvendo economias que o mercado não pode compensar sob forma de preço e lucro (educação, saúde, cultura e pesquisa científica), não há razão para serem privados. Por outro lado, uma vez que não implicam o exercício do poder do Estado, não há razão para que sejam controlados pelo Estado. Se não têm, necessariamente, de ser propriedade do Estado, não há razão para que sejam controlados pelo Estado. Se não têm, necessariamente, de ser propriedade do Estado nem de ser propriedade privada, a alternativa é adotar-se o regime da propriedade pública não estatal, isto é, utilizar organizações de direito privado, mas com finalidades públicas, sem fins lucrativos. "Propriedade pública" é aqui utilizado no sentido de que se deve dedicar ao interesse público, que deve ser de todos e para todos e que não visa ao lucro; "não estatal", no sentido de que não é parte do aparelho do Estado.
\end{abstract}

Em sintonia com as ideias de Friedman (1985), a educação superior e suas pesquisas científicas, a partir dessa perspectiva, passaram a receber um maior investimento por parte do setor privado, submetendo a produção da ciência à lógica do mercado. Como resultado das medidas de caráter neoliberal, observou-se a expansão galopante do ensino superior privado e, anos mais tarde (2004), com a adoção do Programa Universidade para Todos (Prouni), em formato de bolsas, operacionalizou-se o público não estatal.

Na Educação Básica, os organismos internacionais, antes mesmo do governo de FHC, já exerciam influências, como foi no caso da Conferência de Educação para Todos, realizada em 1990, em Jomtien, na Tailândia. O Brasil foi um dos 155 participantes e, nessa conferência, o país assinou um acordo definindo a educação como obrigação de todos, 
contribuindo para que o Estado dividisse seu papel de ofertar a educação escolar com a sociedade civil-empresarial.

Sob a ofensiva neoliberal, as universidades públicas são ameaçadas a ficar numa permanente crise tanto de ordem política como orçamentária. O discurso neoliberal, com o propósito de retirar do Estado a obrigação direta pelo financiamento do ensino superior, advoga que as instituições devem possuir autonomia para, de forma empreendedora, captar "parceiros" para seu financiamento. Com efeito, em 1994, criaram-se as fundações de apoio de direito privado para que, instaladas dentro das universidades públicas, pudessem receber subsídios privados, mediante venda de cursos, pesquisas, projetos, entre outros. Como forma de sobreviver ao novo modelo imposto, as universidades se viram obrigadas a produzir conhecimentos de interesse do mercado para que eles as financiassem, se adaptando ao mercado global.

Enquanto as universidades públicas se adaptavam a esse novo modelo, as instituições privadas cresciam de maneira rápida com recursos do governo federal, por meio de Programas que repassam dinheiro público para custeio de bolsas em universidade particulares, financiamento estudantil, financiamento para pesquisa, entre outros.

O movimento privatista em torno do ensino superior brasileiro tem, portanto, uma estreita relação com a "reforma" do Estado, que demandou novos contornos formativos e estruturais nas universidades, constituindo marcos importantes na tarefa de reformar essas instituições. Como aborda Minto (2006), de um lado, houve um crescente beneficiamento das IES privadas e sua consequente expansão, de outro, um processo de privatização interna nas IES públicas principalmente por meio da criação de pós-graduações pagas, nas quais seus docentes bem qualificados dão o status tão almejado para uma maior procura dos cursos e, assim, maior rentabilidade, por meio das fundações de apoio, que passam a ser o veículo legal para que investimentos privados adentrem nessas instituições públicas. Reforçamos, portanto, que o processo de privatização do ensino superior tem sido duplo: de um lado, há uma intencionalidade na crise das universidades públicas e; de outro, acontece um incentivo para que as universidades e faculdades particulares se expandam com recursos públicos.

Conforme Sguissardi (2002), no período de 18 anos, entre 1980 e 1998, o número de instituições públicas federais permaneceu praticamente o mesmo. Já as instituições privadas passaram de 764 para 2.016 em menos de dez anos. Mas, se considerarmos os dados de 2008, constatamos um enorme crescimento das instituições privadas, alcançando 89,5\% das IES no Brasil, sendo que, no mesmo ano, apenas 10,5\% das IES eram públicas. Essa evolução é ainda mais significativa, se considerarmos o período de 1995 a 2014, no qual as instituições 
privadas representam 87,4\% do ensino superior e as públicas 12,6\%. De 1995 a 2014 o setor privado cresceu enormemente, totalizando 2069 instituições.

Apesar do crescimento do número de instituições públicas, depois de um grande período de estagnação, o setor público ainda representa uma pequena parcela frente ao setor privado, que vem em crescimento desde 1998 não apenas no número de instituições, mas também no número de matrículas. Em 1995 a oferta privada concentrava 60,2\% das matrículas, em 2014 esse mesmo número chegou a 74,9\%. O setor público de 1995 a 2014 cresceu no número de matrículas, mas em relação a todo o ensino superior representou apenas $25 \%$.

A expansão do ensino superior público se deu principalmente a partir de instituições de âmbito federal e um dos programas responsáveis foi o Programa de Apoio a Planos de Reestruturação e Expansão das Universidades Federais (Reuni). O Reuni surge como um programa de governo estabelecido pelo Plano de Desenvolvimento da Educação (PDE). Lima (2009) ressalta que as metas do Reuni não foram propostas inteiramente novas apresentadas para o ensino superior, pois as medidas impostas pelo Programa seguiram a cartilha de reformas elaboradas pelo Banco Mundial para os países subdesenvolvidos.

A adesão ao Reuni expressa uma política de precarização e quebra do modelo de universidade centrada no ensino, pesquisa e extensão. $\mathrm{O}$ aumento progressivo de alunos até atingir o número de 18 por professor e a criação de novos currículos com base em uma formação aligeirada tornam evidentes dois tipos de precarização, a do trabalho docente e a da formação profissional. Como aborda Lima (2009), a Universidade se tornou uma instituição com foco no ensino pragmático, cada vez mais submetida à lógica do mercado.

O Prouni, por sua vez, é uma manifestação clara de como os governos brasileiros operam no alargamento dos ganhos dos empresários do ensino superior, mediante a renúncia fiscal do Estado. O Programa foi instituído pela Medida Provisória n ${ }^{\circ} 213$ do Governo de Luís Inácio da Silva (Lula) e regulamentado pela Lei $n^{\circ}$ 11.096/05. Consiste na concessão de bolsas de estudos parciais ou integrais para estudantes que tenham cursado o ensino médio completo em escolas públicas ou em escolas privadas na condição de bolsista integral, para cursar a graduação em IES privada. Como forma de contrapartida, o governo oferece isenção de impostos às IES privadas que aderirem ao Prouni (CARVALHO, 2006 apud MACHADO; ROCHA, 2011, p. 384).

Um dos problemas do Prouni consiste no fato de que não há para todos os bolsistas subsídios financeiros extras para que eles possam se manter nos cursos. Para se obter a bolsa integral, a renda familiar do estudante deve ser de, no máximo, um salário mínimo e meio. 
Com uma renda de tão baixo valor, torna-se extremamente complicado manter um estudante em uma IES privada tendo que arcar com material didático, alimentação, deslocamento e outras despesas não previstas no Programa. Posteriormente à sua implementação, a Medida Provisória $\mathrm{N}^{\circ} 251$, de 14 de junho de 2005, autorizou a concessão de bolsa-permanência no valor de R\$300,00 mensais, mas somente para estudantes matriculados em cursos com horário integral. Tal medida beneficiou parte dos alunos, mas deixou desassistidos outros estudantes que também possuem despesas, mesmo em cursos que sejam em períodos parciais. A iniciativa mostrou-se importante, mas insuficiente para atender a todos os estudantes que buscam se graduar nessas instituições (MACHADO; ROCHA, 2011).

Outra forma de aumentar o acesso ao ensino superior foi com a expansão da Educação à Distância $(\mathrm{EaD})$. Em 2005, foi criada a Universidade Aberta do Brasil pelo Ministério da Educação em parceria com a Andifes e empresas estatais. No período de 2013 a 2014, essa modalidade de ensino apresentou a taxa de crescimento de $17,8 \%$, o que representa 1.341 .842 matrículas em cursos de graduação, a rede privada concentra 89,6\% dessas matrículas.

Outro programa de incentivo à expansão das IES privadas foi o Fundo de Financiamento ao Estudante do Ensino Superior (FIES), instituído através da lei 10.260, de 12 de julho de 2001 (BRASIL, 2001), o qual concede ao estudante cursar uma graduação em uma IES privada, pagando o curso somente após ter se formado.

Diante de programas como FIES e Prouni, fica claro que o modelo de ensino superior vem sendo alterado com relevante aumento da participação do setor privado na sua oferta. A continuidade do FIES está clara na meta 12 do PNE (Lei $\mathrm{n}^{\circ} 13.005 / 14$ ), na qual propõe expandir o FIES e progressivamente dispensar a obrigatoriedade de um fiador. Dados do relatório de gestão do FIES comprovaram que o Programa está em contínuo crescimento, em 1999 o programa atendia a 67.202 estudantes, em 2000 houve um acréscimo de 35.299, totalizando 102.501 estudantes beneficiados.

Em 2011, cerca de 153 mil novos estudantes foram beneficiados, representando um crescimento de $102 \%$ em contratações quando comparado a 2010. No ano seguinte, o crescimento chegou a $140 \%$ com relação a 2011. Em 2013, o Fundo propiciou acesso a mais de 557 mil estudantes e em 2014, houve cerca 732.243 alunos beneficiados para os cursos de graduação em instituições de educação superior pertencentes a 1.290 entidades mantenedoras com adesão ao Fies. (BRASIL, 2016).

Em cenário de contrarreforma, o modelo alemão humboldtiano centrado no ensino, pesquisa e extensão vem sendo deixado de lado em troca das graduações em curtos períodos, oferecidas a qualquer custo ou até mesmo à distância, com padrões questionáveis de ensino. 
As IES privadas tornaram-se verdadeiros "escolões", nos quais é dada a importância máxima ao lucro em detrimento do acesso aos conhecimentos científicos úteis a toda sociedade.

Destarte, para compreender a situação do ensino superior brasileiro desde os anos de 1990 aos tempos hodiernos, faz-se mister relacioná-lo às medidas neoliberais que atingem tanto o Estado como a educação superior, redefinindo os papeis de um e de outra, para melhor se ajustarem aos interesses expansionistas do mercado. Com efeito, é sob a ordem do ajuste estatal que o atual governo de Bolsonaro investe contra as Instituições Públicas de Ensino Superior (IPES), sob uma ofensiva muito mais grave do que a de anos anteriores.

Está em curso o mais brutal desmonte do ensino superior público, que se desdobra na política dita de contingenciamento, na retirada progressiva de investimentos nas IPES, na intervenção direta para indicação de reitores, atropelando a rodo a autonomia universitária e, mais recentemente, pela imposição do projeto Programa Institutos e Universidades Empreendedoras e Inovadoras (Future-se).

Ainda como esboço de lei, o texto do Future-se anuncia, sem subterfúgios, a nova proposta de ensino superior público, alinhada ao mercado. Nele, a autonomia universitária se veste de empreendedorismo salvacionista que tem o propósito de captar investidores privados, de alocar espaços públicos das IES, de quebrar o regime de dedicação exclusiva dos professores para que estes, também como empreendedores, vendam sua força de trabalho ao mercado.

O Future-se retoma um dos pilares básicos de sustentação da contrarreforma do Estado desde FHC, uma vez que pretende submeter a universidade à gestão de uma Organização Social $(\mathrm{OS})^{8}$, cujo raio de ação é muito mais privatista do que as Fundações de Apoio (criadas em 1994), na medida em que operará não só na gestão de contratos, como monitorará metas de funcionamento da pesquisa, do ensino e da extensão. Para garantir a implementação do Future-se nas universidades brasileiras, o governo de Bolsonaro tem se cercado de estratagemas importantes como a imposição no quadro de reitores de nomes de gestores de sua confiança, na contramão dos primeiros colocados nas listas tríplices, sobrepujando a tradição democrática na escolha desse cargo. Resta-nos a resistência para nos contrapor com excelência acadêmica e compromisso social a esse nefasto ataque à ciência e ao país.

\footnotetext{
${ }^{8}$ As Organizações Sociais foram implementadas ainda na gestão de FHC, no curso acelerado de sua contrarreforma estatal, e ganhou destaque expressivo, editada inclusive como um dos famosos cadernos do Mare (Caderno 2).
} 


\section{Considerações finais}

Os resultados da pesquisa nos revelaram que a problemática do modo de produção do sistema capitalista enfrentou maiores desafios principalmente a partir da década de 1970 . Com o fim da chamada "era de ouro", obtida a partir do crescente lucro, o modo de produção fordista tem seu esgotamento e novos desafios aparecem nos países centrais para manter os lucros perante a crise do sistema.

A flexibilização do modo de produção trouxe novas perspectivas não somente na produção, mas, também, na educação da classe trabalhadora que foi cada vez mais sendo treinada para o desenvolvimento das competências em detrimento dos conhecimentos científicos.

A economia passou a exigir um Estado cada vez menor para atender seus interesses e aumentar seu lucro por meio de serviços, principalmente na saúde e educação. Assim, a educação superior deixou de ser um direito e passou a ser um serviço não exclusivo do Estado, abrindo espaço para a atuação de instituições privadas, com objetivo de lucrar e também formar mão de obra para atuar no mercado. Toda essa mudança foi motivada pelo neoliberalismo, implantado mundialmente. Vale destacar que aqui no Brasil a ofensiva neoliberal foi bem mais perversa do que nos países centrais, pois nesses países os ganhos em saúde e educação estavam mais consolidados, diferente do Brasil que nunca apresentou grandes avanços nesses serviços para a população.

Ao examinarmos a "reforma" do Estado brasileiro e suas consequências na forma como o governo passou a gerenciar as universidades, verificamos que a implementação do que denominamos de contrarreforma do Estado ganhou força dentro do governo FHC com o Plano de Reforma do Estado coordenado por Bresser Pereira, à frente do Ministério de Administração e Reforma do Estado. Medidas foram tomadas para "enxugar" o Estado brasileiro, abrindo um maior espaço de atuação para o setor privado.

A capilaridade das ideias do Estado neoliberal atinge sobremaneira o ensino superior, que já é um setor que conta com recursos insuficientes para uma educação de qualidade, submetido às recomendações dos organismos multilaterais que "recomendam" ampliar a participação do setor privado nessa área a expandir o ensino superior por meio da EaD.

No período que compreende todo o governo FHC (1995-2003) e os governos do Partido dos Trabalhadores (2003-2016), observa-se uma crescente participação do setor privado na oferta de vagas no ensino superior. Para as universidades públicas, a década de 1990 foi de poucos recursos e nenhum crescimento significativo na oferta de vagas, o oposto 
do que ocorreu na iniciativa privada que concentrou maior número de alunos. A mudança de governo na esfera federal não alterou em parte essa lógica, a iniciativa privada continuou seu crescimento por meio de programas de transferência de recursos públicos para as IES privadas.

Essa pesquisa examinou a expansão do ensino superior entre os anos de 1995 e 2014. Mas, à guisa de concluir essas análises, destacamos que a temática em tela merece estudo criterioso na atual conjuntura brasileira pós-golpe de 2016. Da curta gestão de Michel Temer (2016-2018) ao atual governo de extrema direita de Bolsonaro (2019), a contrarreforma do Estado brasileiro vem sendo retomada com maior intensidade. Um conjunto de "reformas"9 vem sendo aprovadas destruindo os direitos duramente conquistados pela classe trabalhadora, comprometendo seu futuro e suas já parcas condições de vida.

Soma-se às investidas ultra-neoliberais na economia, um conjunto de medidas de caráter antidemocrático, cerceadoras das liberdades de expressão que atingem frontalmente a ciência e a cultura. Nesse quadro dantesco, marcado por retrocessos de toda ordem, as universidades públicas são duramente atacadas, tendo seus orçamentos "contingenciados"/reduzidos e sua autonomia cerceada. O sucateamento das universidades públicas, já em franca implementação, promove, assim, as condições ideais para que as instituições privadas possam se espraiar, fomentadas por recursos públicos e alardeadas como instituições modernas, eficazes e eficientes.

Nesse quadro de ataques, o Future-se passa a ser a materialização direta e acelerada da privatização interna das IES, ajustando-as aos moldes neoliberais, mediante a venda direta de projetos, ensino e ciência.

À classe trabalhadora resta a luta para manter seu direito de frequentar a universidade pública, gratuita e de qualidade, altercando um projeto de ciência que possa atender às suas necessidades formativas e proporcionar a produção de conhecimentos que não sejam reféns do mercado, mas que possam ir ao encontro das necessidades do conjunto da humanidade.

\section{Referências}

ANTUNES, R. L. C. Os sentidos do trabalho: ensaio sobre a afirmação e a negação do trabalho. São Paulo, SP: Boitempo, 2009.

\footnotetext{
${ }^{9}$ Entre elas destacam-se as "reformas" trabalhista, a Lei da terceirização e a atual "reforma" da Previdência. 
ANTUNES, R. L. C. Adeus ao trabalho?: ensaio sobre metamorfoses e a centralidade do mundo do trabalho. 5. ed. São Paulo: Cortez; 1998.

BIANCHETTI, R. G. Modelo neoliberal e políticas educacionais. São Paulo: Cortez, 2001

BOITO JR., A. Política neoliberal e sindicalismo no Brasil. São Paulo: Xama, 1999.

BORGES, A. As arapucas do toyotismo. 2005. Disponível em: http://alainet.org/active/8041\&lang=es. Acesso em: 29 jul. 2019.

BRASIL. Ministério da Educação. Planejando a próxima década. 2014. Disponível em: http://pne.mec.gov.br/. Acesso em: 5 jun. 2019.

BRASIL. Ministério da Educação. Prestação de contas ordinárias anual relatório de gestão do exercício de 2014. 2015. Disponível em: http://portal.mec.gov.br/index.php?option=com_content\&view=article\&id=14949\&Itemid=1 064. Acesso em: 14 jun. 2018.

BRESSER-PEREIRA, L. C. Do Estado patrimonial ao gerencial. In: PINHEIRO, S.; SACHS, I.; WILHEIM, J. (org.). Brasil: um século de transformações. São Paulo: Cia. das Letras, 2001. p. 222-259.

CARCANHOLO, M. D.; BARUCO, G. C. C. A estratégia neoliberal de desenvolvimento capitalista: caráter e contradições. Praia Vermelha, Rio de Janeiro, v. 21, n. 1, p. 9-23, jul./dez. 2011. Disponível em: http://www.academia.edu/5149574/Neoliberalismo. Acesso em: 20 jul. 2019.

CARINHATO, P. H. Neoliberalismo, reforma do Estado e políticas sociais nas últimas décadas do século XX no Brasil. Revista Aurora, Marília, v. 2, n. 1, 2011. Disponível em: http://www2.marilia.unesp.br/revistas/index.php/aurora/article/view/1192. Acesso em: 10 ago. 2019.

COSTA, L. C. O governo FHC e a reforma do Estado Brasileiro. Pesquisa \& Debate, São Paulo, v. 11, n. 1, p. 49-79, 2000. Disponível em: http://revistas.pucsp.br/index.php/rpe/article/view/11922.. Acesso em: 25 set. 2019.

FRIEDMAN, M. Capitalismo e liberdade. São Paulo: Nova Cultural, 1985. (Coleção Os Economistas).

HARVEY, D. A condição pós-moderna: uma pesquisa sobre as origens da mudança cultural. 2. ed. São Paulo: Loyola, 1992.

LIMA, K. Contra-reforma da educação nas universidades federais: o Reuni na UFF. Universidade e Sociedade, Brasília, n. 44, p. 147-157, jul. 2009.

MACHADO E ROCHA, A. R. Prouni e a expansão do ensino superior privado: a política pseudodemocratizante de acesso ao ensino superior do Governo Lula. In: MENEZES, A. M. D. et al. (org.). Trabalho, educação, Estado e a crítica marxista. 3. ed. Fortaleza: Edições UFC, 2011. p. 379-397.

MARX, K. O capital: o processo de produção do capital. Livro I, v. 2, 2002. 
MESZAROS, I. A crise estrutural do capital. São Paulo: Boitempo, 2002.

MINTO, L. W. A educação superior na particularidade do capitalismo brasileiro: sentido histórico e questões para os movimentos sociais. In: SEMINÁRIO NACIONAL DE ESTUDOS E PESQUISAS HISTÓRIA, SOCIEDADE E EDUCAÇÃO NO BRASIL, 9., 2012. Anais [...]. Paraíba: Editora da Universidade Federal da Paraíba, 2012.

MINTO, L. W. Educação superior, trabalho docente e capitalismo no Brasil: problematizando o ensino à distância $(\mathrm{EaD})$. In: SEMINÁRIO DO TRABALHO: TRABALHO, EDUCAÇÃO, SOCIALIDADE, 7., 2010. Anais [...]. Marília: Editora da UNESP, 2010.

MIRANDA, F. As interpretações marxistas da crise econômica atual: uma análise com base na teoria das crises de Marx. 2011. Dissertação (Mestrado em Economia) - Instituto de Economia, Universidade Federal do Rio de Janeiro, Rio de Janeiro, 2011.

PANIAGO, C. Neoliberalismo e os antecedentes da "crise" do estado. In: ENCONTRO NACIONAL DE PESQUISADORES EM SERVIÇO SOCIAL - ENPESS, 11., 2008, Anais [...], São Luis: ABEPSS; UFMA, 2008.

SGUISSARDI, V. Fundações privadas na Universidade Pública: a quem interessam? Avaliação, Campinas, v. 7, n. 4, p.43-72, dez. 2002.

TUMOLO, P. S. Reestruturação produtiva no Brasil: um balanço crítico introdutório da produção bibliográfica. Educ. Soc. [online], v. 22, n. 77, p. 71-99, 2001. Doi: 10.1590/S010173302001000400005.

ZANARDINI, I. M. S. A reforma do Estado e da educação no contexto da ideologia da PósModernidade. Perspectiva, Florianópolis, v. 25, n. 1, p. 245-270, 2007.

Submetido em 9 de agosto de 2019.

Aprovado em 20 de outubro de 2019. 